\title{
Complete Atrioventricular Block Complicating Inferior Wall Acute Myocardial Infarction Treated with Reperfusion Therapy
}

\author{
Peter Clemmensen, MD, Eric R. Bates, MD, Robert M. Califf, MD, Mark A. Hlatky, MD, \\ Lynne Aronson, BS, Barry S. George, MD, Kerry L. Lee, PhD, Dean J. Kereiakes, MD, \\ Gerald Gacioch, MD, Eric Berrios, RN, Eric J. Topol, MD, and the TAMI Study Group*
}

Previous studies report larger myocardial infarcts and increased in-hospital mortality rates in patients with Inferior wall acute myocardlal Infarction (AMI) and complete atrioventricular block (AV), but the clinical implications of these complications in patients treated with reperfusion therapy have not been addressed. The clinical course of 373 patients- $50(13 \%)$ of whom developed complete AV block- admitted with inferior wall AMI and given thrombolytic therapy within 6 hours of symptom onset was studied. Acute patency rates of the infarct artery after thrombolytic therapy were similar in patients with or without AV block. Ventricular function measured at baseline and before discharge in patients with complete AV block showed a decrement in median ejection fraction $(-3.5$ vs $-0.4 \%, p=0.03$ ) and in median regional wall motion ( -0.14 vs +0.24 standard deviations/chord, $p$ $=0.05$ ). The reccclusion rate was higher in patients with complete AV block (29 vs $16 \%, p=$ 0.03). Patients with complete AV block had more episodes of ventricular fibrillation or tachycardia (36 vs 14\%, p <0.001), sustained hypotension (36 vs $10 \%$, p $<0.001$ ), pulmonary edema (12 vs $4 \%$,

From the Division of Cardiology, Department of Medicine, Duke University, Durham, North Carolina; Division of Cardiology, Department of Internal Medicine, University of Michigan, Ann Arbor, Michigan; The Riverside Methodist Hospital, Columbus, Ohio; and the Christ Hospital, Cincinnati, Ohio. This study was presented in part at the American College of Cardiology, 38th Scientific Session, Anaheim, California, and supported in part by research grants from Genentech Inc., San Francisco, California, Abbott Laboratories, Chicago, Illinois and by Research Grants HS-05635 and HS-04873 from the Agency for Health Care Policy and Research, Rockville, Maryland, by Research Grants HL-17670 and HL-36587 from the National Heart, Lung, and Blood Institute, Bethesda, Maryland, and by grants from the Robert Wood Johnson Foundation, Princeton, New Jersey. Manuscript received April 16, 1990; revised manuscript received and accepted September 26, 1990.

Address for reprints: Robert M. Califf, MD, Duke University Medical Center, Division of Cardiology, P.O. Box 31123, Durham, North Carolina 27710.

\footnotetext{
*See Appendix.
}

$p=0.02)$ and a higher in-hospilal mortality rate (20 vs 4\%, p <0.001), although the mortality rate after hospltal discharge was Identical $(2 \%)$ in the 2 groups. Muttivariable logistic regression analysis revealed that complete AV block was a strong independent predictor of in-hospital mortality $(p=$ 0.0006). Thus, despite initial successful reperfusion, patients with inferior wall AMI and complete AV block have higher rates of in-hospital complications and mortality.

(Am J Cardiol 1991;67:225-230)

I nferior wall acute myocardial infarction (AMI) is often complicated by atrioventricular (AV) block. Before the widespread use of thrombolytic therapy, complete AV block occurred in 8 to $13 \%$ of such patients during the hospital course. ${ }^{1-3}$ Several investigators report that larger infarctions are associated with AV block and that a high incidence of in-hospital complications and an increased short-term mortality rate occur among patients with complete AV block..$^{1-3}$ The long-term outcome of hospital survivors, however, seems unaffected by the occurrence of complete AV block during hospitalization. ${ }^{1,4}$ One previous study suggested that complete $\mathrm{AV}$ block in patients with an inferior wall myocardial infarction is associated with coexistent multivessel disease. ${ }^{5}$ The aforementioned studies were all conducted in the prethrombolytic era. The clinical implications of complete AV block in patients treated with reperfusion therapy have not been addressed. Whether the occurrence of complete heart block is an independent risk factor for mortality has not been evaluated, because acute coronary anatomic and left ventricular function findings have not been available. We therefore undertook the present study to describe the clinical course and prognostic significance of complete AV block complicating inferior wall AMI in patients treated with reperfusion therapies.

\section{METHODS}

Patient population: The study population was culled from 810 consecutive patients who participated in 4 
clinical trials conducted by the Thrombolysis and Angioplasty in Myocardial Infarction (TAMI) study group, which studied different thrombolytic therapeutic strategies. Briefly, patients admitted within 6 hours of symptom onset with an AMI were enrolled if they met the following criteria: electrocardiographic evidence of epicardial injury, defined as $\geq 0.1 \mathrm{mV}$ ST-segment elevation in $\geq 2$ contiguous leads; absence of previous $Q$-wave infarction in the distribution of the acute ischemic region; and chest pain $\geq 30$ minutes' duration unresponsive to standard sublingual nitroglycerin therapy. Patients were ineligible for the study if they had a history of a significant bleeding diathesis or a known bleeding disorder, a history of gastrointestinal or genitourinary bleeding within the preceding 4 weeks, a stroke in the past 6 months, major surgery in the preceding 2 weeks, uncontrolled hypertension (diastolic blood pressure repeatedly $>110 \mathrm{~mm} \mathrm{Hg}$ ), other serious advanced illness, cardiogenic shock (systolic blood pressure $<85 \mathrm{~mm} \mathrm{Hg}$ unresponsive to volume expanders), prolonged cardiopulmonary resuscitation in the preceding 2 weeks, severe trauma within the past 6 months, psychological or physical inability to participate, or if they were women of child-bearing potential.

Patients underwent acute cardiac catheterization and the cineangiograms were recorded for later, independent analysis by a control angiographic core laboratory. The culprit infarct artery was determined to be the left anterior descending artery in 307 patients, the left circumflex artery in 104 patients and the right coronary artery in 373 patients. The remaining 26 patients had occlusion of the left main stem, or coronary bypass grafts, or the infarct artery could not be determined. Complete AV block occurred in 62 patients (8\%). This complication was almost entirely limited to patients with right coronary artery-related infarction $(n=50)$ and rarely occurred with left anterior descending ( $\mathrm{n}=$ $6)$ or left circumflex artery $(n=6)$ infarction. The focus of this study was therefore confined to the $373 \mathrm{pa}-$ tients with inferior wall AMI because of occlusion of the right coronary artery. Written informed consent was obtained from all patients before entry into studies. Enrollment of patients into the 4 studies began December 10, 1985, and ended March 24, 1988.

Data collection and definitions: Data pertaining to baseline characteristics, treatment and outcome were collected by research nurses and audited by a second nurse before analysis. Specific characteristics pertaining to complete heart block (duration, associated features) were collected on an ancillary data form by research nurses and fellows. Complete heart block was defined by standard clinical criteria: complete dissociation of the atrial and ventricular rates, with the atrial rate greater than the ventricular rate.

In most cases cardiac rhythm strips were available, but, in some instances, clinical observation of the cardiac monitor led to the diagnosis even though a hard copy was not available. The definitions of clinical variables have been published previously. ${ }^{6-9}$

Follow-up information was obtained by telephone or self-administered questionnaires given to patients or nearest relatives. The last follow-up contact occurred at a median of 22 months after hospital discharge; followup was $97 \%$ complete.

Thrombolytic regimen: Intravenous thrombolytic therapy was given to all patients. Of the 386 patients enrolled in the TAMI-1 trial, the first 178 patients received recombinant tissue-type plasminogen activator at a dose of $60 \mathrm{mg} /$ hour during the first hour, $20 \mathrm{mg} /$ hour during the second and third hours and $10 \mathrm{mg} /$ hour in the last 5 hours. The remaining 208 patients received 1 $\mathrm{mg} / \mathrm{kg}$ in the first hour (to a maximum dose of $90 \mathrm{mg}$ ), with the remainder of the dose given continuously as a 5-hour infusion for a total dose of $150 \mathrm{mg}$. All patients had $10 \%$ of the first hourly dose administered as a bolus injection over 6 minutes. ${ }^{6}$ Of the 147 patients in the TAMI-2 study, 34 patients received $25 \mathrm{mg}$ of singlechain recombinant tissue-type plasminogen activator in addition to urokinase ( 0.5 to 1.0 million units of urokinase). The remaining 112 patients received $1 \mathrm{mg} / \mathrm{kg}$ of tissue plasminogen activator in addition to urokinase in varying doses $(0.5,1.5$ and 2.0 million units, respectively). ${ }^{7}$ The 175 patients in the TAMI-3 study received 1.5 $\mathrm{mg} / \mathrm{kg}$ recombinant tissue-type plasminogen activator. Half the patients received a bolus dose of heparin on hospital admission and all received a full dose of heparin 90 minutes after infusion of recombinant tissue-type plasminogen activator. ${ }^{8}$ The 102 patients in the urokinase study received 3 million units over 45 to $60 \mathrm{~min}$ utes. ${ }^{9}$

Angiographic studies: All patients underwent diagnostic cardiac catheterization with angiographic visualization of all 3 major coronary arteries and a left ventriculogram $\geq 90$ minutes after the administration of thrombolytic therapy. All patients received 5,000 units of intravenous heparin subsequent to arterial access. Quantitative estimation of the flow in the infarct-related coronary artery was performed by Thrombolysis in Myocardial Infarction (TIMI) classification criteria. ${ }^{10}$ Arteries with TIMI flow grade 0 or 1 were considered occluded and arteries with flow grade 2 or 3 were considered patent. Reocclusion was defined in patients not occluded upon leaving the diagnostic catheterization as recurrent total occlusion of the infarct-related artery. Lesion location was defined as proximal or distal in relation to the first right ventricular branch of the right coronary artery. Percutaneous transluminal coronary angioplasty was performed when anatomically feasible in all patients with a TIMI flow grade of 0 to $1 . \mathrm{Pa}$ tients with TIMI flow grade 2 or 3 underwent percutaneous transluminal coronary angioplasty in accordance with the different protocols (by randomization in TAMI-1, and if clinical evidence of ongoing ischemia persisted in TAMI-2, TAMI-3 and the urokinase study). When acute percutaneous transluminal coronary angioplasty was performed, an additional 5,000 units of heparin were given. In patients with angiographically visible filling defects suggesting the presence of residual thrombus, $30 \mathrm{mg}$ of intracoronary recombinant tissue-type plasminogen activator or 300,000 units of intracoronary urokinase were administered. An effort was made to perform a repeat cardiac catheterization in 


\begin{tabular}{|c|c|c|}
\hline & $\begin{array}{l}\text { Complete AVB } \\
(n=50)\end{array}$ & $\begin{array}{l}\text { No Complete AVB } \\
(n=323)\end{array}$ \\
\hline $\begin{array}{l}\text { Age (median, } \\
\text { interquartile range) }\end{array}$ & $60(53-66)$ & $57(49-64)$ \\
\hline Male gender (\%) & $37(74)$ & $257(80)$ \\
\hline History of smoking $(\%)$ & $31(62)$ & $217(67)$ \\
\hline Diabetes (\%) & $10(20)$ & $41(13)$ \\
\hline Family history of $\mathrm{CAD}(\%)$ & $19(38)$ & $153(47)$ \\
\hline Hypertension (\%) & $19(38)$ & $136(42)$ \\
\hline Hyperlipidemia (\%) & $4(8)$ & $43(13)$ \\
\hline History ol angina (\%) & $19(38)$ & $151(48)$ \\
\hline $\begin{array}{l}\text { Time to } R x \text { (median in } \\
\text { minutes, interquartile } \\
\text { range) }\end{array}$ & $159(120-197)$ & $170(122-214)$ \\
\hline Multivessel disease ${ }^{*}(\%)$ & $15(30)$ & $133(42)$ \\
\hline
\end{tabular}

all patients as close as possible to the seventh day after hospital admission. Global left ventricular ejection fraction was determined by the area-length method ${ }^{11}$ and regional wall motion of the infarct zone by the centerline chord method. ${ }^{12}$ Both the acute and predischarge angiographic studies were analyzed at the angiographic core laboratory by independent observers.

Hospital care: All patients were admitted to the coronary care unit, where cardiac rhythm was routincly monitored for 24 hours. Medical therapy included intravenous lidocaine for 24 hours, 1 enteric-coated aspirin tablet $(325 \mathrm{mg})$ per day and diltiazem $(60 \mathrm{mg})$ every 6 hours for 7 days. Heparin was administered by intravenous infusion up to 7 days to a level of activated partial thromboplastin time 1.5 to 2.5 times greater than control values. Beta blockers were only administered when clinically indicated (supraventricular tachycardia, hypertension or angina pectoris). All additional revascularization procedures, including percutaneous transluminal coronary angioplasty or coronary artery bypass grafting, were performed as clinically indicated at the discretion of the attending physician. Temporary transcutaneous $^{13}$ or transvenous pacemakers were used at the discretion of the treating physician.

Data analysis: Unless otherwise indicated, all continuous variables describing patient characteristics were described in terms of the median and interquartile range. Discrete variables were described by frequencies and percentages. Group differences in proportions were examined with the chi-square test. Patient groups were compared with respect to continuous variables by the 2sample Wilcoxon rank-sum test. Two-sided p values $<0.05$ were considered statistically significant. Multiple logistic regression analysis was performed to determine the importance of complete AV block as a predictor of in-hospital mortality relative to other prognostic clinical and angiographic variables.

\section{RESULTS}

Complete AV block was observed in 50 of the 373 patients (13\%) with an AMI related to the right coro-
TABLE II Clinical Characteristics of Complete

Atrioventricular Block in 50 Patients Treated with Reperfusion Therapy

\begin{tabular}{|c|c|}
\hline $\begin{array}{l}\text { Duration in hours } \\
\text { (median, interquartile range) }\end{array}$ & $2.5(1-12)$ \\
\hline Precipitating clinical events (\%) & $19(38)$ \\
\hline Reperfusion (\%) & $5(10)$ \\
\hline PTCA $(\%)$ & $7(14)$ \\
\hline Reocclusion (\%) & $7(14)$ \\
\hline \multicolumn{2}{|l|}{ Immediate complications of AVB } \\
\hline Hypotension (\%) & $35(73)$ \\
\hline $\mathrm{VT} / \mathrm{VF}(\%)$ & $10(20)$ \\
\hline Asystole (\%) & $8(17)$ \\
\hline
\end{tabular}

nary artery. No substantial differences in clinical baseline characteristics were found between the 2 groups (Table I), although the patients with complete AV block did appear to have a slightly lower percentage of multivessel disease and a lower percentage of a history of angina pectoris.

Figure 1 shows the time from onset of chest pain to the first recorded episode of complete AV block. In $54 \%$ of patients, complete AV block was present on admission and developed in all except 2 patients within 72 hours after symptom onset. Immediate treatment of complete AV block included temporary pacemakers in $60 \%$ of the paticnts. In $8 \%$, the pacemaker was inserted prophylactically, before the development of complete AV block. Atropine was administered to $82 \%$ of the patients with complete AV block. The block was transient in all but 1 patient, who required insertion of a permanent pacemaker after aortocoronary bypass surgery. Duration of complete AV block was $\leq 1$ hour in $25 \%$ of the patients and $<12$ hours in $75 \%$ (median duration 2.5 hours). Complete AV block could be associated with chemical reperfusion, angioplasty or reocclusion in $38 \%$ of patients (Table II). Immediate complications associated with the development of complete AV block occurred often and included hypotension, ventricular tachycardia, ventricular fibrillation and asystole.

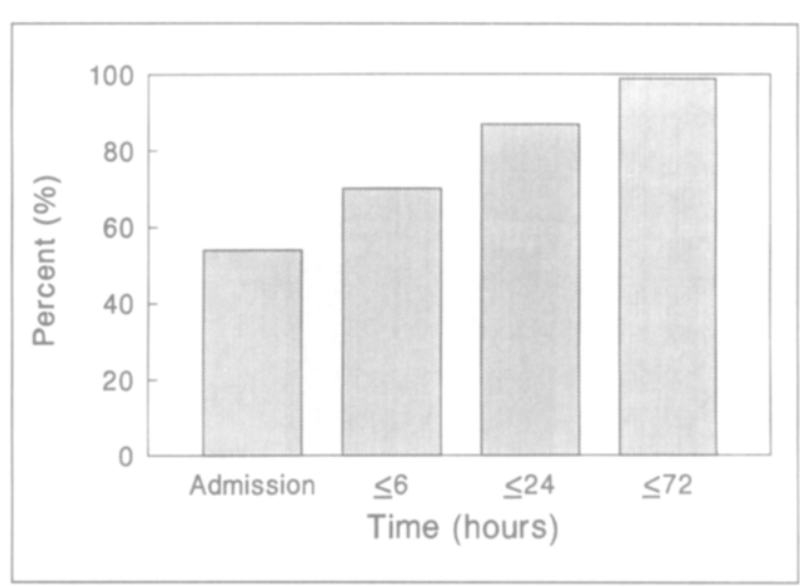

FIGURE 1. Cumulative percentage of patients developing complete atrioventricular block $\leq 6,24$ and 72 hours after onset of myocardial infarction. 


\begin{tabular}{|c|c|c|}
\hline & $\begin{array}{l}\text { Complete AVB } \\
(n=50)\end{array}$ & $\begin{array}{l}\text { No Complete AVB } \\
(n=323)\end{array}$ \\
\hline Proximal lesion (\%) & $28(56)$ & $144(45)$ \\
\hline Distal lesion (\%) & $22(44)$ & $179(55)$ \\
\hline \multicolumn{3}{|l|}{ Acute findings $(\%)$} \\
\hline 90-min patency* & $33(66)$ & $222(69)$ \\
\hline Acute PTCA & $24(48)$ & $129(40)$ \\
\hline Final patency ${ }^{\top}$ & $45(90)$ & $294(91)$ \\
\hline \multicolumn{3}{|l|}{ Predischarge findings } \\
\hline Patency (\%) & $27(71)$ & $226(82)$ \\
\hline Reocclusion (\%) & $13(29)$ & $46(16)$ \\
\hline $\begin{array}{l}\text { * First diagnostic angiog } \\
\text { † Final patency = infarc } \\
\text { mechanical interventions. } \\
\text { Abbreviations as in Tabble }\end{array}$ & $\begin{array}{l}\text { y patency status aft } \\
\text { II. }\end{array}$ & ute pharmacologic an \\
\hline
\end{tabular}

The infarct artery status is summarized in Table III. There was no difference between the patency of the infarct artery after thrombolytic therapy and the patency after acute catheterization: $90 \%$ in patients with and $91 \%$ in those without complete AV block. However, patency before hospital discharge was $11 \%$ lower in the patients with complete AV block because of a higher reocclusion rate ( 29 vs $16 \%, \mathrm{p}=0.03$ ).

Global and regional left ventricular function data are shown in Figures 2 and 3. At acute angiography, the mean ejection fraction in the group with complete AV block was $56 \%$, compared with $55 \%$ in the group without. At follow-up angiography, there was no change in the ejection fraction in patients without complete AV block, but there was a $3.5 \%$ decrease in the group with complete AV block $(p=0.03)$. The mean acute infarct zone wall motion was -2.49 standard deviations/chord with complete AV block and -2.39 standard deviations/chord without. Before discharge, acute infarct zone wall motion improved in the group without complete AV block and decreased further in the group with complete AV block. The trend toward more functional recovery of the infarct zone among patients without complete AV block was of borderline statistical significance $(\mathrm{p}=0.05)$.

The clinical outcomes of the 2 groups are listed in Table IV. The in-hospital course was more complicated

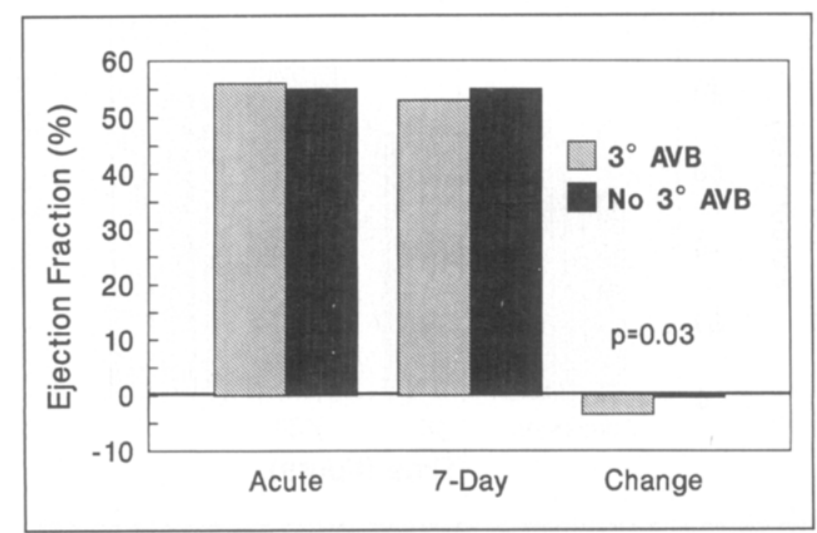

FIGURE 2. Global left ventricular ejection fraction as determined by contrast ventriculography for the 2 groups, Values represent means of paired acute and predischarge studies. AVB = atrioventricular block.

\begin{tabular}{|c|c|c|c|}
\hline & $\begin{array}{l}\text { Complete } \\
\text { AVB } \\
(n=50)\end{array}$ & $\begin{array}{l}\text { No Complete } \\
\text { AVB } \\
(n=323)\end{array}$ & $p$ Value \\
\hline $\begin{array}{l}\text { VT/VF (\%) (Unrelated to } \\
\text { bradycardia) }\end{array}$ & $18(36)$ & $46(14)$ & $<0.001$ \\
\hline Sustained hypotension (\%) & $18(36)$ & $33(10)$ & $<0.001$ \\
\hline Congestive heart failure (\%) & $13(26)$ & $17(5)$ & $<0.001$ \\
\hline Pulmonary edema $(\%)$ & $6(12)$ & $13(4)$ & 0.02 \\
\hline In-hospital mortality (\%) & $10(20)$ & $12(4)$ & $<0.001$ \\
\hline $\begin{array}{l}\text { Long-term mortality (\%) } \\
\text { (22-month follow-up) }\end{array}$ & $1(2)$ & $6(2)$ & NS \\
\hline
\end{tabular}

in the patients who developed complete AV block. Ventricular fibrillation or tachycardia occurred in 36 vs $14 \%$ and sustained hypotension in $36 \mathrm{vs} 10 \%$, respectively. Ten of the 50 patients with complete AV block (20\%) died in-hospital versus only 12 of 323 without (4\%) $(p<0.001)$. The long-term mortality rates of the hospital survivors after a median follow-up of 22 months were identical (2\%) in the 2 groups.

The independent prognostic value of complete AV block was examined by logistic regression analysis. When age, acute left ventricular ejection fraction, number of diseased vessels and TIMI grade flow were entered into a multivariable logistic regression model, complete AV block contributed independent prognostic information concerning in-hospital mortality (chisquare $=11.6, \mathrm{p}=0.0006$ ).

\section{Discussion}

The major finding of this study was that the incidence of complete AV block in patients with AMI treated with thrombolytic therapy is similar to the incidence reported before the thrombolytic era. ${ }^{1-3,5,14}$ Furthermore, when compared with historical populations, the mortality rate in the group of patients who developed complete AV block was not lower, despite aggressive reperfusion attempts, usually with success in this population. ${ }^{1-3,14,15}$ Our findings of a somewhat more depressed regional and global left ventricular function are

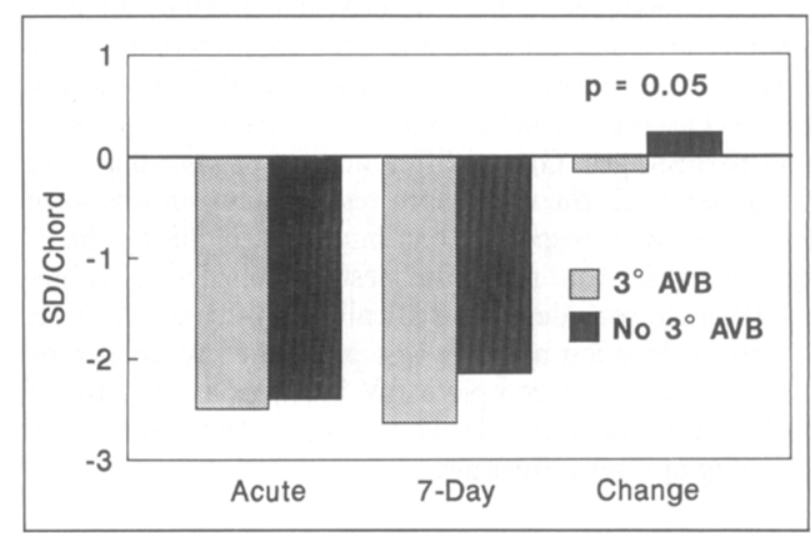

FIGURE 3. Regional wall motion of the infaret zone as determined by the centerline chord method for the 2 groups. Values represent means of paired acute and predischarge studies. SD $=$ standard deviations; other abbreviation as in Figure 2 . 
in agreement with those of previous studies that describe larger infarcts and more depressed left ventricular function in the patients who developed complete AV block compared with those who did not. ${ }^{1-3,15}$

A recent study by Nicod et al $^{1}$ involving patients who did not undergo thrombolytic intervention found that complete AV block was an independent factor for in-hospital prognosis when correcting for other noninvasive factors known to be important for prognosis. This finding was confirmed in the present study, where complete AV block was a strong predictor of in-hospital mortality, even after considering variables obtained via cardiac catheterization, including acute left ventricular ejection fraction, number of diseased vessels and TIMI grade flow after thrombolytic therapy. Long-term prognosis of hospital survivors was good in the present study and unaffected by the development of complete AV block in the hospital. Other studies conducted in the prethrombolytic era have reported similar results. ${ }^{1,16}$

In the present as well as in previous studies, complete AV block was transient in almost all patients. ${ }^{1,3,17}$ According to Hackel et al, ${ }^{18}$ the transient nature of complete AV block in these patients is probably due to the relative resistance of the conduction system to ischemia. These investigators summarized several mechanisms that, alone or in combination, could cause transient complete AV block in these patients, all of which could be altered by myocardial reperfusion. Reperfusion could diminish the severity of local metabolic changes and the total duration of ischemia of the AV node. Conversely, restoration of anterograde blood flow to previously ischemic myocardium might both facilitate leukocyte migration to the infarcted area and stimulate vagal nerve endings in the inferoposterior aspects of the left ventricle. ${ }^{18}$ Based on the findings in the present study, it appears that the major effect of reperfusion on the natural history of complete AV block is to minimize its duration, possibly because the ischemic burden on the AV node is relieved. Indeed, the 2.5-hour median duration of the $3^{\circ} \mathrm{AV}$ block in this study is the shortest ever reported in a large series of patients.

In the present study, complete AV block was associated with an active component of reperfusion therapy (reperfusion, angioplasty or reocclusion) in $38 \%$ of patients, raising the possibility that reperfusion could itself provoke the AV block. Clinicians should thus be prepared for this complication to arise when other clinical markers of reperfusion occur, when angioplasty is chosen as an adjunctive therapy or when the patient develops clinical signs of reocclusion.

A recent study hypothesized that patients who develop acute AV block have a high incidence of multivessel disease, particularly co-existing obstruction of the left anterior descending artery. ${ }^{5}$ That study comprised only 51 patients, and the 32 patients with $\geq 75 \%$ stenosis of the left anterior descending artery had a $31 \%$ incidence of AV block versus a $1 \%$ incidence among the patients without significant disease of that artery. Our findings are in agreement with another recent large study of 749 patients, which failed to detect such a relation. ${ }^{1}$

Study limitations: The ideal study design for answering the question of the impact of $3^{\circ} \mathrm{AV}$ block on patient outcome after thrombolytic therapy would include a control group not undergoing any clinical attempt at myocardial reperfusion. However, such a study would be almost impossible to conduct in the present era, and our comparisons are therefore limited to findings of previous studies conducted before the widespread use of reperfusion therapies. The clinical definition of AV block used in this study is not as complete as what could be achieved by continuous Holter monitoring of a large population. Transient episodes of complete AV block could have been missed, or, in some cases, AV dissociation could have been erroneously labeled as heart block. Nevertheless, these findings are representative of current practice in institutions with a full-time cardiology staff observing patients with AMIs. Also, the critical question of right ventricular involvement in patients with complete AV block cannot be answered by the present study, because right ventricular infarction was not routinely assessed in this population. A previous study has found that the right ventricle is involved in the majority of patients with inferior wall myocardial infarction who develop advanced AV block. ${ }^{15}$

Acknowledgment: We are indebted to Galen $\mathrm{S}$. Wagner, MD, for valuable advice and critical review of this manuscript, and to Lisbeth Mattisson and Sandy Pendergraph for expert manuscript preparation.

\section{REFERENCES}

1. Nicod P, Gilpin E, Dittrich H, Polikar R, Henning H, Ross J Jr. Long-term outcome in patients with inferior myocardial infarction and complete atrioventricular block. I Am Coll Cardiol 1988;12:589-594

2. Gupta PK, Lichstein E, Chadda KD. Heart block complicating acute inferior wall myocardial infarction. Chest 1976;69:599-604.

3. Tans AC, L ie KI, Durrer D. Clinical setting and prognostic significance of high degree atrioventricular block in acute inferior myocardial infarction: a study of 144 patients. Am Heart $J$ 1980;99:4-8.

4. Thygesen K, Haghfelt T, Steinmetz E, Lyager Nielsen B. Long-term survival after myocardial infarction as related to early complications. Eur $J$ Cardiol $1977 ; 6: 41-51$

5. Bassan R, Maia IG, Bozza A, Amino JGC, Santos M. Atrioventricular block in acute inferior wall myocardial infarction: harbinger of associated obstruction of the left anterior descending coronary artery. $J$ Am Coll Cardiol 1986;8:773-778. 6. Topol EJ, Califf RM, George BS, Kereiakes DJ, Abbottsmith CW, Candela RJ, Lee KL, Pitt B, Stack RS, O'Ncill WW, and The Thrombolysis and Angioplasty in Myocardial Infarction (TAMI) Study Group. A randomized trial of immediate vs delayed elective angioplasty after intravenous tissue plasminogen activator in acute myocardial infarction. $N$ Engl $J$ Med 1987;317:581-588.

7. Topol EJ, Califf RM, George BS, Kereiakes DJ, Rothbaum D, Candela RJ, Abbottsmith CW, Pinkerton CA. Stump DC, Collen D, Lee KL, Pitt B, Kline EM, Boswick JM, O'Neill WW, Stack RS, and the TAMI Study Group. Coronary arterial thrombolysis with combined infusion of recombinant tissue-type plasminogen activator and urokinase in patients with acute myocardial infarction. Circulation 1988;77:1100-1107.

8. Topol EJ, George BS, Kereiakes DJ, Stump DC Candela RJ, Abbottsmith CW, Aronson L, Pickel A, Boswick JM, Lee KL, Ellis SG, Califf RM, and the TAMI Study Group. A randomized controlled trial of intravenous tissue plasminogen activator and early intravenous heparin in acute myocardial infarction. Circulation 1989;79:281-286.

9. Wall TC, Strickland J, Masoud J, Tse A, Pasi D, Zawodniak M, Anderson J, Hoekstra J, Mantell S, Sigmon K, Stack RS, Phillips HR, Califf RM. Thrombolytic therapy on the homefront. Intravenous urokinase in community hospitals. NC Med J 1989;50:363-366.

10. The TIMI Study Group. The Thrombolysis in Myocardial Infarction (TIMI) trial. N Engl J Med 1985;312:932-936.

11. Sandler H, Dodge HT. The use of single plane angiocardiograms for the calculation of left ventricular volume in man. Am Heart $J$ 1968;75:325-334. 12. Sheehan FH, Bolson EL, Dodge HT, Mathey DG, Schofer J, Woo H. Advantages and applications of the centerline method for characterizing regional ventricular function. Circulation 1986;74:293-305.

13. Worlcy SJ, Bride WM. External transthoracic pacing in patients with acute 
myocardial infarction. In: Califf RM, Wagner GS, eds. Acute Coronary Care 1987. Boston: Martinus Nijhoff, 1987:191-201.

14. Feigl D, Ashkenazy J, Kishon $Y$. Early and late atrioventricular block in acute inferior myocardial infarction. $J$ Am Coll Cardiol 1984;4:35-38.

15. Strasberg B, Pinchas A, Arditi A, Lewin RF, Scharovsky S, Hellman C, Zafrir N, Ayman J. Left and right ventricular function in inferior acute myocardial infarction and significance of advanced atrioventricular block. $\mathrm{Am} \mathrm{J} \mathrm{Cardiol}$ 1984;54:984-987.

16. Lassers BW. First year follow-up after recovery from acute myocardial infarction with complete heart block. Lancet 1969;1:1172-1174.

17. Sclarovsky S, Strasberg B, Hirshberg A, Ardifi A, Lewin RF, Agmon J. Advanced early and late atrioventricular block in acute inferior wall myocardial infarction. Am Heart $J$ 1984;108:19-24.

18. Hackel DB, Wagner GS, Ratliff NB, Cies A, Estes EH. Anatomic studies of the cardiac conduction system in acute myocardial infarction. Am Heart $J$ $1972 ; 83: 77-81$

\section{APPENDIX}

The Thrombolysis and Angioplasty in Myocardial Infarction Study Group: University of Michigan, Ann Arbor: Eric J. Topol, MD (Principal Investigator), William W. O'Neill, MD, Joseph A. Walton, MD, Eric R. Bates, MD, Stephen G. Ellis, MD, M. Anthony Schork, PhD, Eva Kline, RN, BSN, Laura Gorman, RN, BSN, Raymond Worden, BS, Bertram Pitt, MD. ANGIOGRAPHIC CORE LABORATORY: Raymond Worden, BS, Cindy L. Grines, MD, Mark Sanz, MD, Eric J. Topol, MD. SATELLITE CENTERS: Foote Hospital, Jackson, Michigan: Gregory Baumann, MD, John Maino, MD, Mary Ann
Mengelson, MD, Constance Doyle, MD, Patricia Lamb, MD. South Macomb Hospital, Warren, Michigan: Stanley Wolfe, MD, Leonard Bayer, DO, Armando Madrazo, MD, Robert Moore, MD.

Duke University, Durham, North Carolina: Robert M. Califf, MD (Cu-Principal Investigator), Richard S. Stack, MD, Harry R. Phillips, III, MD, Peter Quigley, MD, Robert H. Peter, MD, Ken Morris, MD, Victor Behar, MD, Y. Kong, MD, Charles Simonton, MD, Thomas Bashore, MD, Eric Carlson, MD, Susan Mantell, RN, BS. BIOSTATISTICAL CORE LAbORATORY: Kerry L. Lee, PhD, Kristina Sigmon, MA, S. Lynn Harrelson-Woodlief, MS, Lynne Aronson, BS, Jane M. Boswick, MPH, Robert M. Califf, MD. ELECTROCARDIOGRAPHIC CORE LABORATORY: Galen S. Wagner, MD, Peter Clemmensen, MD.

Riverside Methodist Hospital, Columbus, Ohio: Barry S. George, MD, Richard J. Candela, MD, Joanne Dillon, RN, BS, Ramona Masek, RN, BS.

Christ Hospital, Cincinnati, Ohio: Dean J. Kereiakes, MD, Charles W. Abbottsmith, MD, Linda Anderson, RN, BSN, Linda Martin, RN, BSN.

University of Vermont, Burlington, Vermont: HEMATOLOGY CORe Laboratory: David Stump, MD, Desire Collen, MD, PhD, Dagnija Thornton, BS.

DATA MONitoring COMmitTeE: Mark A. Hlatky, MD, Daniel B. Mark, MD, MPH, Kerry L. Lee, PhD. 